\title{
COMPREHENSIVE ASSESSMENT OF THE EFFECTIVE USE OF PACKAGE UNITS TO SORT MUNICIPAL SOLID WASTE
}

\author{
Valentin Penchuk ${ }^{1}$, Vitalii Datsenko², Yurii Novichkov³ \\ 1,2,3 Donbas National Academy of Civil Engineering and Architecture \\ Derzhavina st., 2, Makeevka \\ ${ }^{2}$ dacenko-vital@mail.ru
}

\begin{abstract}
Based on conclusions made in research into municipal waste processing, it is established that the existing technologies using stationary sorting plants most often involve special trucks that compact municipal solid waste (MSW) transported, which results in decreasing the plant efficiency. Preliminary MSW compacting during transportation significantly complicates the sorting process; at the compression ratio , time spent to sort the i-th volume of waste increases up to $30 \%$.

A method proposed to run the feasibility analysis of the process involving the use of a package unit to sort MSW allows establishing the area of its application.
\end{abstract}

\section{Keywords}

Sorting, solid waste, block plant, construction.

\section{Introduction}

In the 21st century, the variety of consumer products is constantly growing, the number of packaging types for product delivery and storage is increasing, therefore, the amount of waste is increasing as well and the environmental situation is deteriorating every year. One of the many sources generating municipal solid waste (MSW) is cultural events. Improving the efficiency of processing MSW generated during mass events and reducing the cost of these operations have always been and will continue to be relevant.

\section{Literature review}

The environmental issue associated with municipal solid waste stays in focus of numerous studies. Several papers (Babanin, 2006; Bilitewski, Dornak, 2006; Bukhgalter et al., 2004; Veprentsev, 2006; Christensen et al., 1999) address various administrative and economic aspects of waste disposal and garbage disposition in inhabited areas. Segregated MSW collection directly at waste generation sites is discussed (Babanin, 12005). Involvement and active participation of local residents represent the most important element in successful implementation of large-scale projects for segregated MSW collection. Modern trends in areas of management, monitoring, and engineering solutions related to the issue of waste management and modern methods of waste processing are explored (Grinin, Novikov, 2002; Kasimov et al., 2007; Krasnyansky, 2007; Podchezertseva, 2005; Chekalin, 2001).

Issues dealing with advantages and prospects of the processing industry in the European Union are addressed (Bontoux et al., 1996; Dubois et al., 2004; Pires et al., 2011; Planning for solid waste \& recycling. City of Boise 


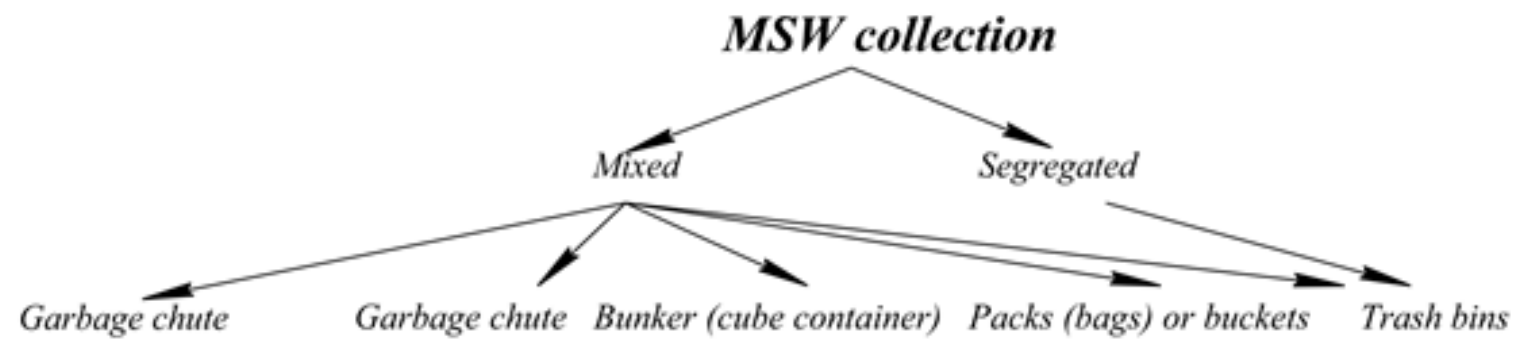

Figure 1. Methods of MSW collection

Planning \& Development Services, 2008). Specifically, the Directive on the prevention of air pollution from new municipal waste incineration plants is considered (Council Directive on the prevention of air pollution from new municipal waste incineration plant, 1989). Methods of waste management in medical facilities and management/ restoration of landfills set up under urban/suburban conditions are studied (Overmann et al., 1999).

\section{Problem statement}

The goal of this study is associated with justifying the efficiency of using package units to sort municipal solid waste.

The following tasks were formulated to achieve the goal:

- identifying types of mass events;

- assessing the impact of the MSW compaction degree on sorting quality and time;

- justifying areas of rational using of package and mobile sorting units, as well as their design features;

\section{Study background}

Mass events involve meetings, rallies, demonstrations, processions, religious (cult) and spiritual/educational meetings, picketing, sport events, cultural and entertainment events, presentation, advertising and other events held in accordance with the effective legislation.

During such events, a certain amount of MSW having specific fraction composition is generated.

Referring to the work of Krasnyansky (2004), we can estimate the amount of recyclables contained in MSW and its accumulation rate.

Table 1. The average content of recyclables in MSW

\begin{tabular}{|l|l|l|l|l|}
\hline $\begin{array}{l}\text { MSW } \\
\text { amount } \\
\left(\mathrm{m}^{3} / \text { per- }\right. \\
\text { son per } \\
\text { day })\end{array}$ & $\begin{array}{l}\text { MSW } \\
\text { amount } \\
\left(\mathrm{m}^{3} / \text { per- }\right. \\
\text { son per } \\
\text { year })\end{array}$ & $\begin{array}{l}\text { MSW } \\
\text { mass }(\mathrm{kg} / \\
\text { person per } \\
\text { day })\end{array}$ & $\begin{array}{l}\text { MSW } \\
\text { density } \\
\left(\mathrm{kg} / \mathrm{m}^{3}\right)\end{array}$ & $\begin{array}{l}\text { MSW composi- } \\
\text { tion } \\
(\% \mathrm{wt})\end{array}$ \\
\hline 0.0029 & 0.99 & 0.59 & 217.1 & $\begin{array}{l}\text { Waste paper } \\
-40 \\
\text { Glass - 25 } \\
\text { Plastics - 15 } \\
\text { Metal - 5 } \\
\text { Other - 15 }\end{array}$ \\
\hline
\end{tabular}

Given that the number of people attending public events can be in the range from 1 to 50 thousand or even more and the average duration of an event can be 3-4 hours, we can talk about the MSW amount of $0.5-25 \mathrm{~m}^{3}$. As is shown in Table 1, the waste fraction composition is almost completely suitable for recycling, which, in turn, indicates a need for waste sorting.

At the present time, there are the following approaches to collect MSW (Figure 1):

- mixed (residents collect MSW generated in daily life in a single container);

- segregated (residents individually sort garbage into fractions).

It is difficult to arrange segregated waste collection in public places during mass events as it is not possible to set up a large number of trash bins and containers for each type of fraction.

Mixed collection implies transportation of waste using specialized public trucks. Modern trucks and equipment for loading and transporting municipal waste are equipped with mechanisms for forced compression with degree $\xi=$ $4 \ldots 5$ to increase the mass of waste transported in a single cycle. Studies on the effect of compacting MSW on the sorting time carried out at the premises of the Donbas National Academy of Civil Engineering and Architecture (Department of Lifting and Transporting, Construction and Road Machinery and Equipment) (Penchuk, Datsenko, 2012,2013 ) showed that, at the compression ratio of 4 , time spent on sorting increased up to $30 \%$ (Figure 2).

In this regard, the most rational is sorting of waste near places of its formation using package units, a design scheme and prototype of which are shown in Figures 5 and 6.

MSW product sorting using a conveyor belt can be referred to as smooth continuous production which ensures the shortest duration of production cycles. Depending on the collection site, MSW products can be sorted into 4-7 fractions.

Equal operating cycles are necessary for continuous production; in such case, the duration of collecting individual fractions should be equal to:

$$
t_{W P}=t_{G}=t_{P E T}=t_{M E T}=t_{T E X}=t_{E S T}
$$

where $t_{W P} ; t_{G} ; t_{P E T} ; t_{M E T} ; t_{T E X}$ are respective intervals of time spent on waste paper, glass, plastic, metal and textiles collection;

$t_{E S T}$ is arbitrary time of conveyor movement or estimated conveyor movement rate. 


\section{Architecture and Engineering Volume 3 Issue 3}

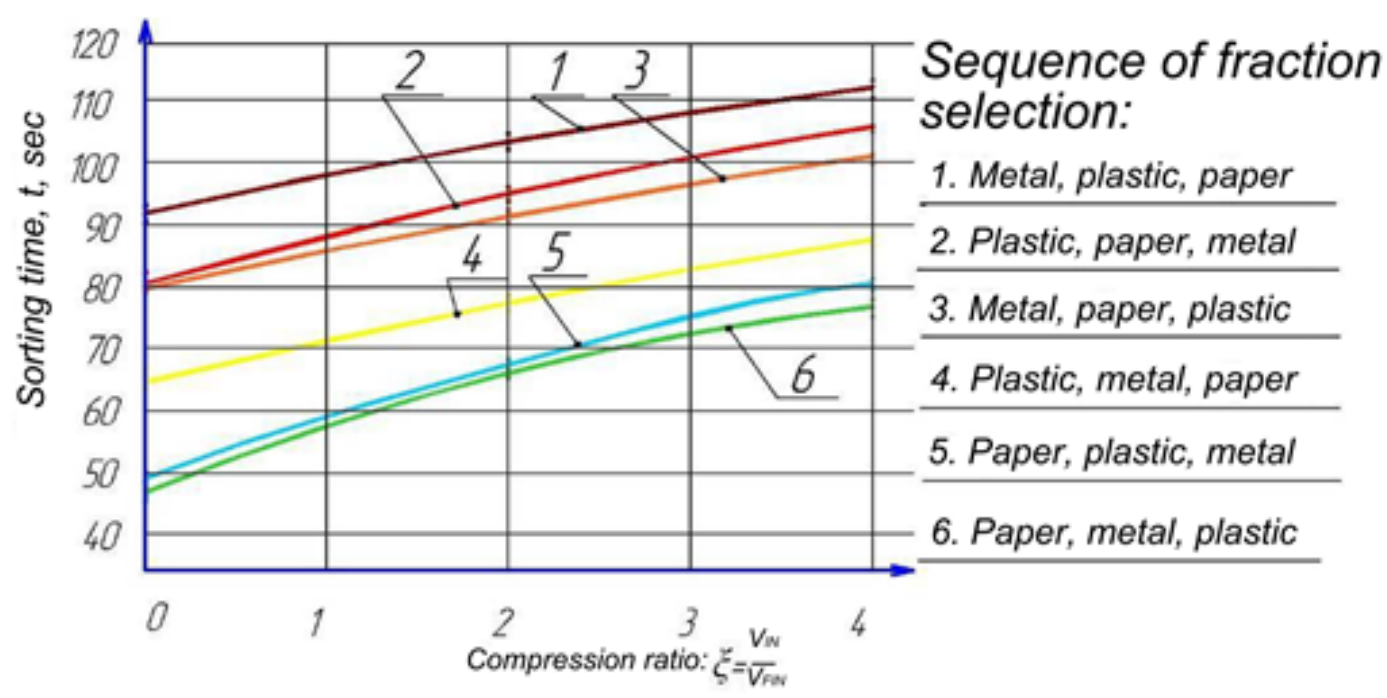

Figure 2. A dependence of the sorting time on the compression ratio and sequence of MSW fraction selection

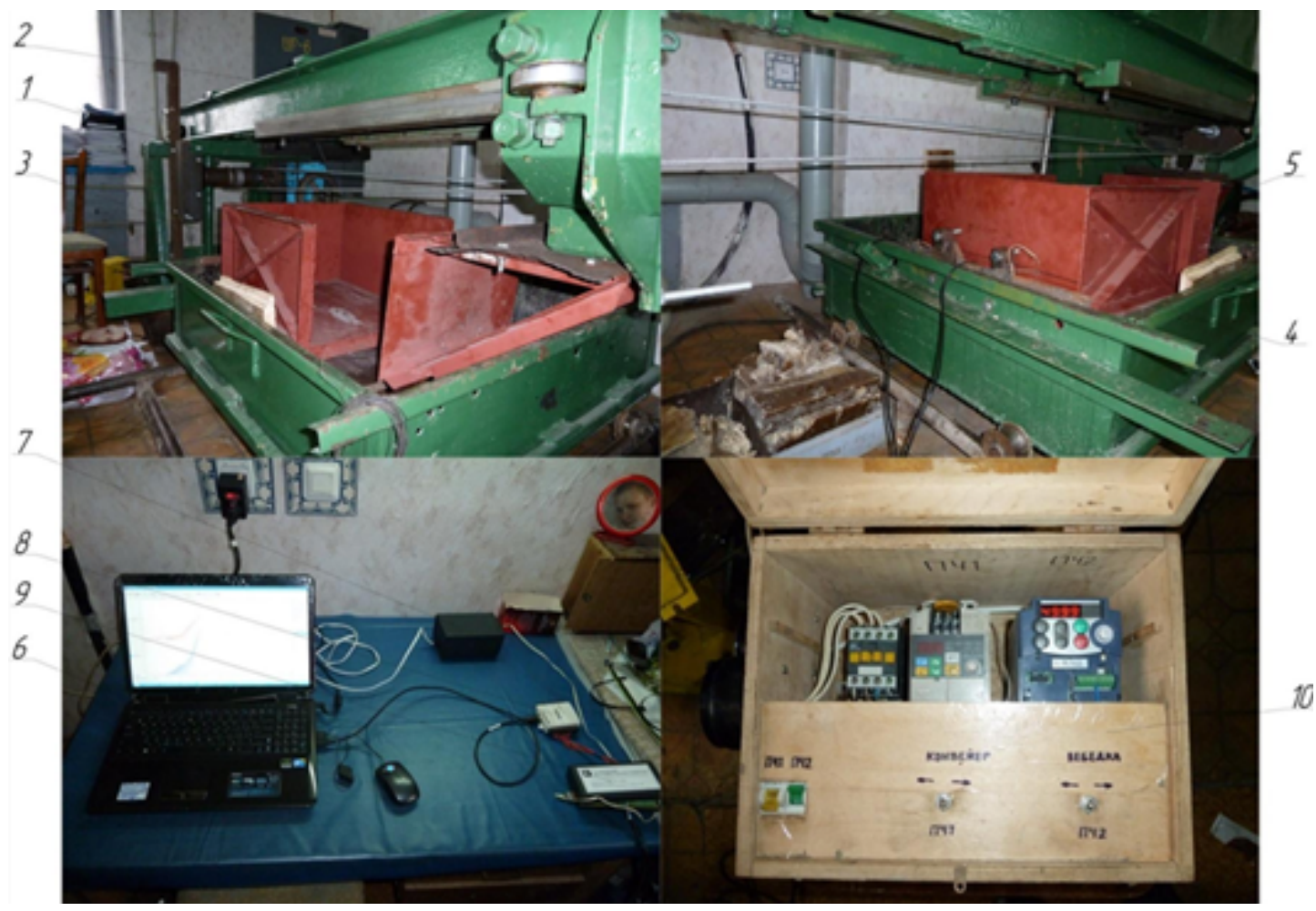

Figure 3. A general view of MSW compaction bench:

1 - a drive; 2 - a bench frame; 3 - a box simulating the garbage truck body; 4 - a sensor to measure the compaction force; 5 - a compactor plate; 6 - a computer; 7 - an amplifier power supply; 8 - a National Instruments controller for signal transformation; 9 - a four-channel amplifier; $10-a$ frequency control unit of the drive.

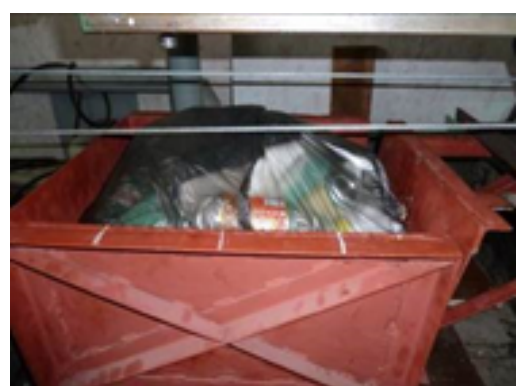

(a)

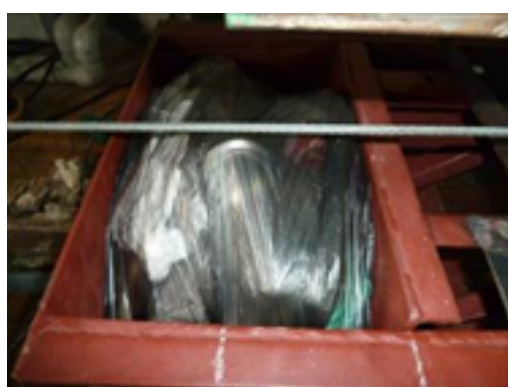

(b)

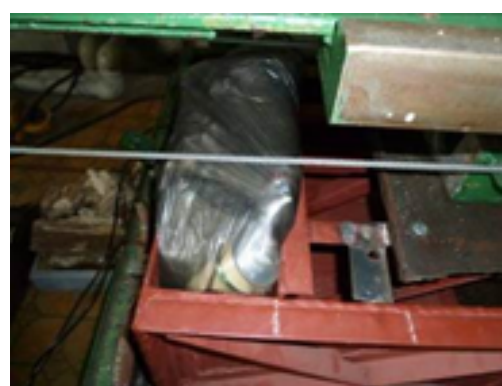

(c)

Figure 4. Phases of MSW compression: a) $\xi=0$; b) $\xi=2$; c) $\xi=4$ 


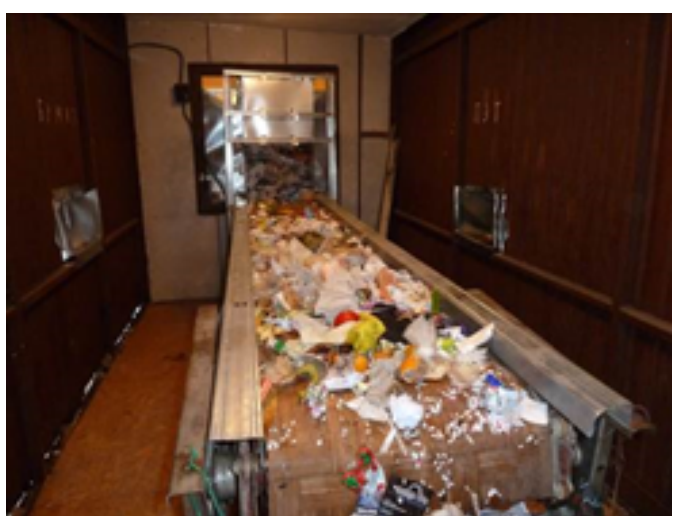

(a)

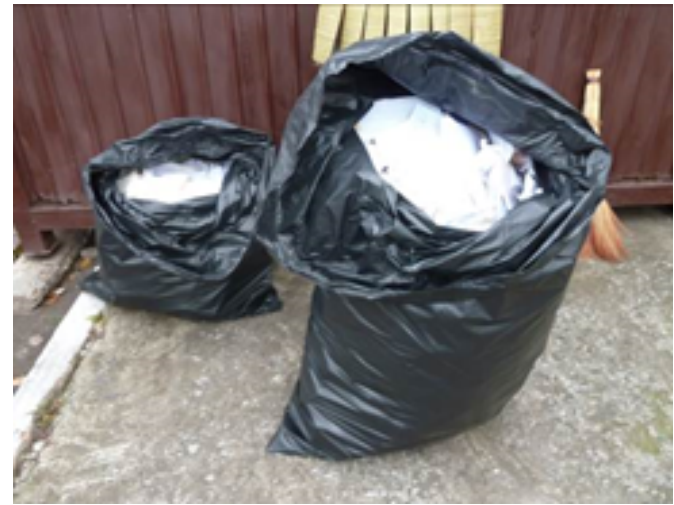

(c)

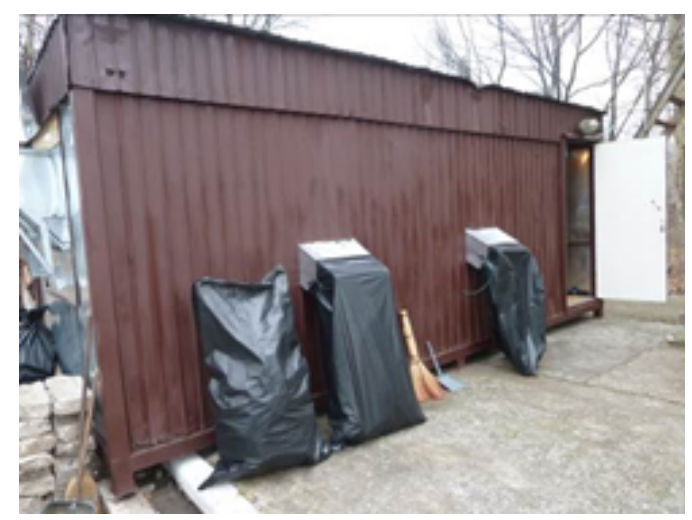

(b)

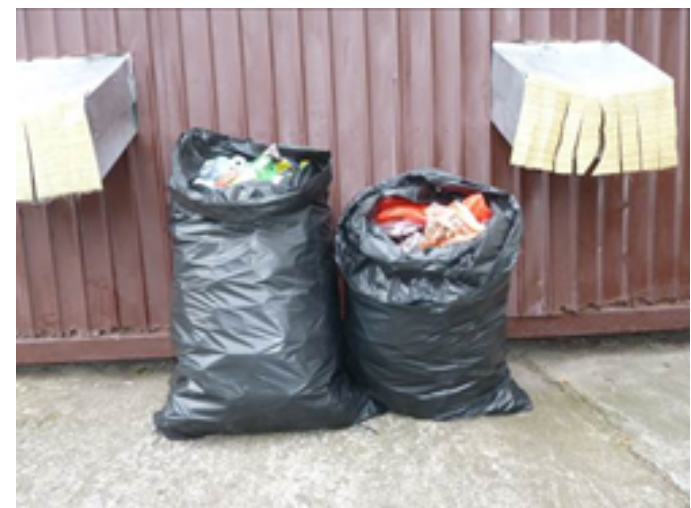

(d)

Figure 5. A package unit for MSW sorting:

a - MSW sorting process; $b$ - process of collecting sorted recyclables; $c$ - sorted waste paper; $d$ - sorted plastic and polyethylene

It is necessary to mention such parameter as estimated conveyor movement mode which entirely depends on physiological capabilities of the operator. Initially, the operator should visually find the required item on the conveyor belt, and, according to the data, time spent for this operation amounts to $t_{v i s}=0.5 \ldots 1 \mathrm{~s}$.

Then the operator performs an operation of manual gripping $t_{\text {grip }}$ moving the item to the receiving opening $t_{\text {mov }}$ and lowering it into the receiving opening $t_{\text {low }}$. Therefore, a working cycle of an operator can be represented as follows:

$$
t_{\text {oper }}=t_{\text {vis }}+t_{\text {grip }}+t_{\text {mov }}+t_{\text {low }}
$$

If we represent the operating conveyor as areas to collect the corresponding MSW components, then the calculation scheme can be given as follows (Figure 7).

The conveyor movement rate can be calculated based on capabilities of the operator. If we denote the length of the working area, which can be handled by a human hand without stress, as $L_{W}$, then the dependence for the estimated time can be written as follows:

$t_{E S T}=\frac{L_{W}}{v_{b}}$

Then the number of working cycles of an operator will amount to:

$$
n_{c}=\frac{t_{E S T}}{t_{\text {oper }}}=\frac{L_{W}}{v_{b}} \cdot \frac{1}{t_{\text {vis }}+t_{\text {grip }}+t_{\text {mov }}+t_{\text {low }}}
$$

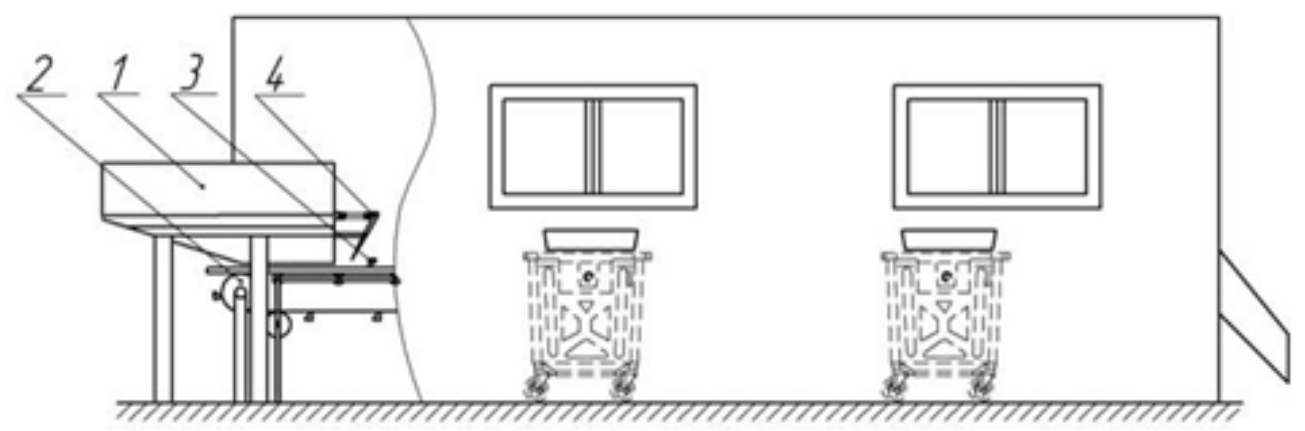

Figure 6. A structural scheme of a package unit:

1 - receiving hopper; 2 - a belt conveyor; 3 - conveyor grips; 4 - spring-loaded blades for tearing and loosening of polyethylene bags 
If we assume that in the amount of MSW located along the estimated length of the conveyor belt section $L_{W}$ there is an $n_{i}$ number of fractions, then the required number of stations to collect those fractions can be represented as follows:

$$
\begin{aligned}
& k_{W P}=\frac{n_{W P}}{n_{c}} ; k_{G}=\frac{n_{G}}{n_{c}} ; k_{P E T}=\frac{n_{P E T}}{n_{c}} \\
& k_{M E T}=\frac{n_{M E T}}{n_{c}} \quad k_{T E X}=\frac{n_{T E X}}{n_{c}}
\end{aligned}
$$

If the required number of stations is more than 1 , then the value obtained is rounded upwards.

The operation of individual stations can be synchronized using numerous technical and organizational arrangements.

Preliminary synchronization can be achieved by combining options of fraction collection:

1) waste paper, glass, PET, metal, textiles;

2) glass, waste paper, PET, metal, textiles;

3) PET, waste paper, glass, metal, textiles;

4) metal, waste paper, glass, PET, textiles;

etc.

In order to select a more rational technology for selecting MSW components, a preliminary experiment on selecting fractions or fine-tuning the sorting line in a production environment should be carried out in the following manner:

- individual staffing to carry out specific operations;

- adjustment of the conveyor belt speed;

- introduction of auxiliary personnel;

- preliminary sorting of large-size fractions.

In accordance with the calculation scheme (Figure 7) and equation (5), the required length of the conveyor belt can be determined using the following equation:

$$
L_{\text {conv }}=L_{W} \cdot\left(k_{W P}+k_{G}+k_{P E T}+k_{M E T}+k_{T E X}\right)
$$

If a certain operation deviates significantly from standard, it is recommended to set up buffer areas or introduce the function of adjusting the conveyor belt speed.

To assess quality indicators of any sorting technology, we can apply the sorting level parameter:

$$
E_{\text {sort }}=\frac{\sum_{i=1}^{n} m_{i}}{m_{\text {TAIL }}}
$$

where $\sum_{i=1}^{n} m_{i}$ is the total MSW mass;

$m_{\text {TAIL }}$ is the mass of material "tailings" remaining after sorting.

A better picture can be obtained through analyzing the structure of MSW tailings. In this case, it will be possible to establish the efficiency of sorting for each fraction:

$$
\begin{aligned}
& E_{\text {sort }}^{W P}=\frac{m_{\text {TAIL }}^{\text {WP }}}{m_{\text {WP }}+m_{\text {TAIL }}} \\
& E_{\text {sort }}^{G}=\frac{m_{\text {TAIL }}^{G}}{m_{G}+m_{\text {TAIL }}}
\end{aligned}
$$

$$
E_{\text {sort }}^{i}=\frac{m_{\text {TAIL }}^{i}}{m_{i}+m_{\text {TAIL }}}
$$

This allows identifying the most important operations and introducing adjustments into the sorting technology.

Parameters of the sorting process mainly depend on the state of od1 operand, or the cost.

The initial state of MSW (od1 operand) means its morphological composition and compression ratio during delivery.

The initial cost of MSW products implies the cost associated with waste collection, storage, loading and delivery. It can still be assumed that MSW itself is free.

Generally, the efficiency function of a particular technology for MSW processing can be written as follows:

$$
E^{M S W}=\sum_{i=1}^{n} \sum_{j=1}^{m} O_{i j} \cdot \gamma_{i j}-\sum_{i=1}^{n} \sum_{j=1}^{m} C_{i j} \rightarrow \max
$$

where $O_{\mathrm{ij}}$ - output from processing of the $i$-th kind of municipal waste using technology $j$;

$\gamma_{i j}$ - contract price of the $i$-th type of municipal waste using technology $j$;

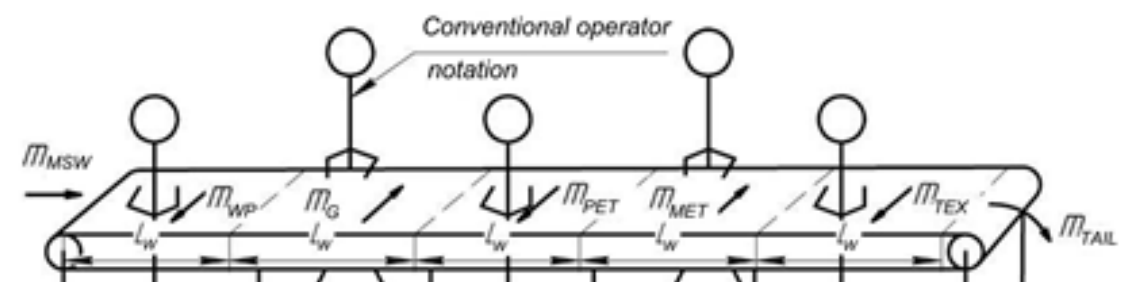

Figure 7. A calculation scheme to collect MSW fractions:

$m_{W P}$ - waste paper; $m_{G}-$ glass; $m_{P E T}-$ plastic; $m_{P E T}-$ metal; $m_{T E X}-$ textiles; $m_{T A I L}-$ tailings; $L_{W}-$ length of the operator's working area. 


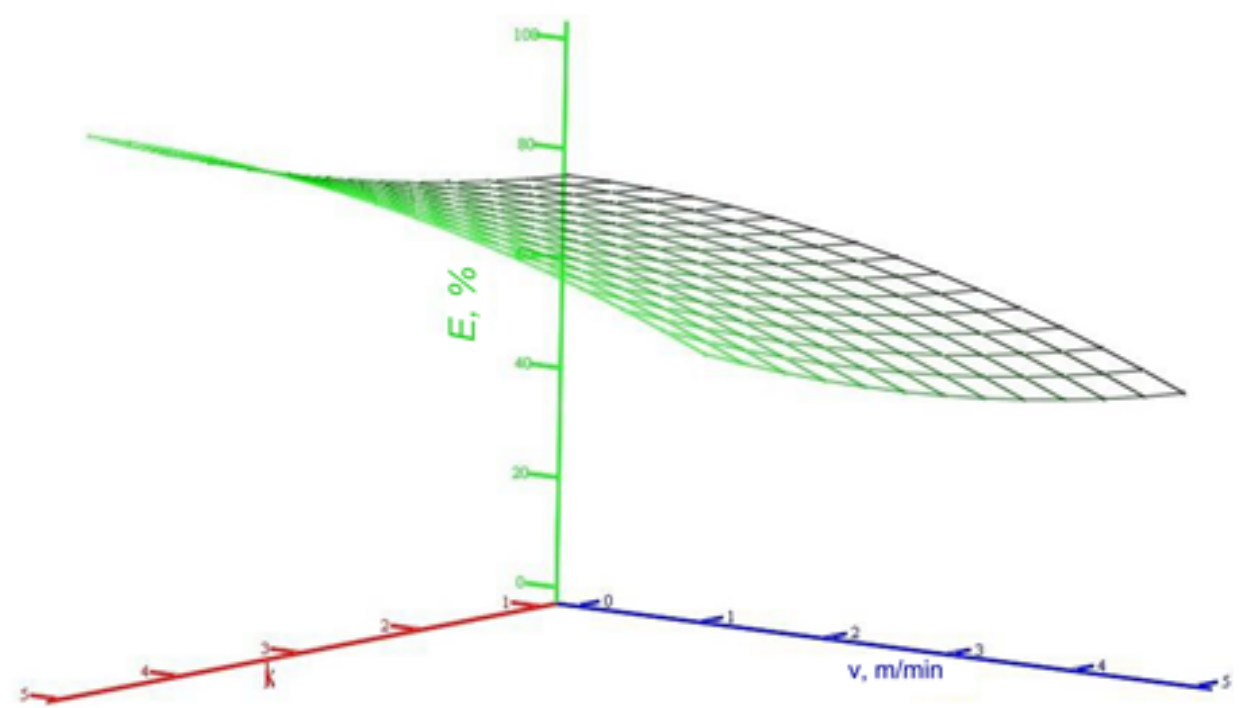

Figure 8. A dependence of the sorting efficiency on the conveyor speed and the number of stations to collect the $i$-th fraction

$C_{\mathrm{ij}}-$ costs for physical and power resources, associated with processing the i-th type of waste using technology $j$;

In order to identify the most rational technology

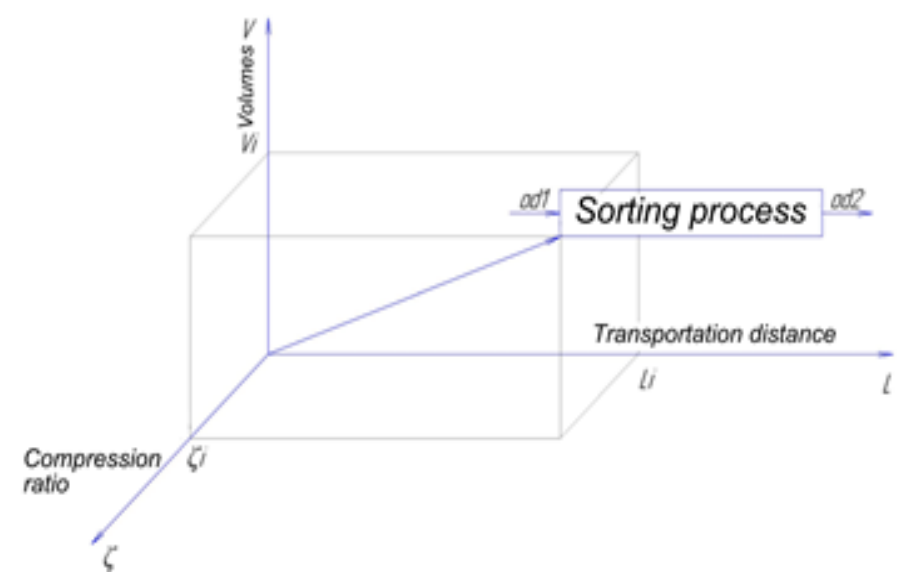

Figure 9. An MSW sorting process:

od1 - an operand of the initial state of MSW products (volume, compression ratio, transportation distance); od2 - an operand of the state of MSW products after sorting (volume, compression ratio, transportation distance)

for processing municipal waste, $j$ directions of MSW movement shall be analyzed.

If we assume that, after sorting into fractions, fraction quantity and quality is the same in all technologies, that the following can be accepted:

$\sum_{i=1}^{n} \sum_{j=1}^{m} O_{i j} \cdot \gamma_{i j} \approx \sum_{i=1}^{n} \sum_{j=1}^{m} O_{i(j+1)} \cdot \gamma_{i(j+1)} \rightarrow \max$

Each individual object (school, university, hospital, recreation center, district, city, etc.) has its own specific MSW characteristics in terms of volume, nature of collection, distance, etc., but in all cases works shall be carried out in an efficient manner and with minimum costs.
In general, the function of cost optimization associated with MSW processing can be expressed as follows:

$$
C_{s p}^{M S W}=\frac{\sum_{i=1}^{n} \sum_{j=1}^{m} C_{i j}}{\sum_{i=1}^{k} O_{i j} \cdot \gamma_{i j}} \rightarrow \min
$$

where $C_{\mathrm{ij}}$ - costs for physical and power resources associated with collecting and transporting $\sum_{i=1} O_{i j}$ of
MSW.

In this case, the efficiency of technology j depends only on particular costs for physical and power resources.

In this case, the efficiency of technology j depends only on particular costs for physical and power resources.

$$
\sum C_{o d 2}=C_{a c c}^{j}+C_{\text {load }}^{j}+C_{d e l}^{j}+C_{s o r t}^{j}
$$

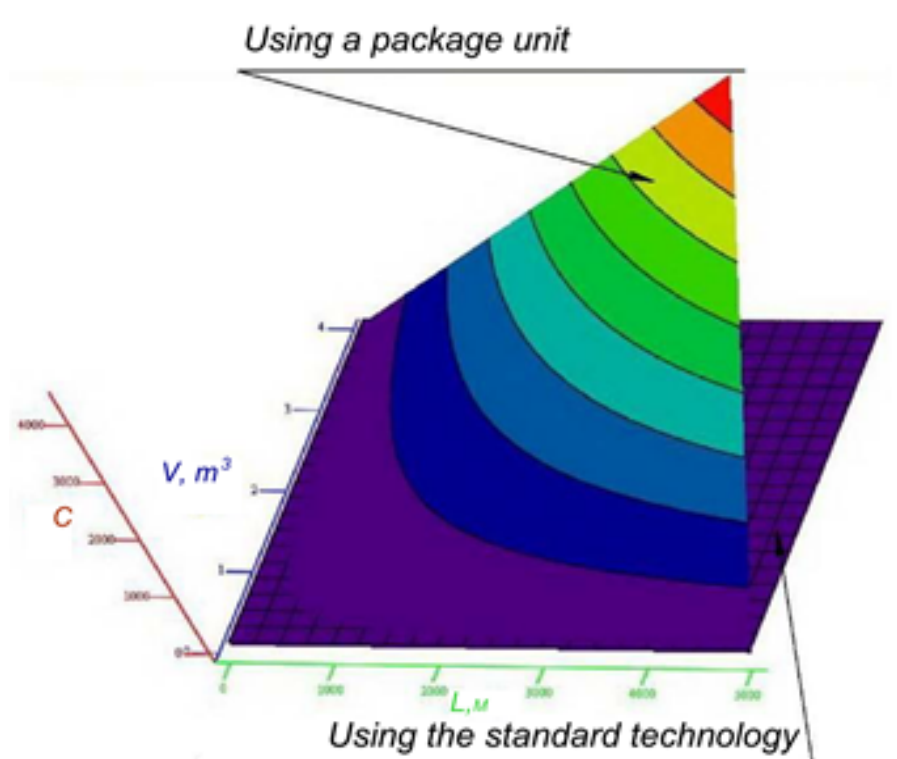

Figure 10. Costs for MSW processing as a function of the volume and transportation distance 
where $C_{\text {acc }}^{j} ; C_{\text {load }}^{j} ; C_{\text {del }}^{j} ; C_{\text {sort }}^{j}$ are costs for physical and power resources, associated with accumulation, loading, delivery and sorting of MSW using technology $j$.

In case the output of MSW processing increases, the specific costs change accordingly. It is necessary to establish the level of specific costs for the $j$-th direction to determine the rational technology for MSW processing under specific conditions taking into account the waste volume and transportation distance.

$$
\frac{\sum_{i=1} C_{\text {od } 2}}{\sum_{i=1}^{n} O_{n}^{j}}=\frac{C_{\text {acc }}^{j}}{\sum_{i=1}^{n} O_{i}^{j}}=\frac{C_{\text {load }}^{j}}{\sum_{i=1}^{n} O_{i}^{j}}=\frac{C_{\text {del }}^{j}}{\sum_{i=1}^{n} O_{i}^{j}}=\frac{C_{\text {sort }}^{j}}{\sum_{i=1}^{n} O_{i}^{j}}
$$

When the volume of MSW processing and the distance of transportation change, the specific costs change accordingly. It is necessary to consider the MSW movement in all possible directions and take the partial derivatives of the following functions in order to find the rational technology for municipal waste processing:

$$
\begin{aligned}
& \frac{d\left(\sum C_{o d 2}^{1}\right)}{d\left(\sum_{i=1}^{n} O_{n}^{1}\right)}=0 \\
& \frac{d\left(\sum^{n} C_{o d 2}^{2}\right)}{d\left(\sum_{i=1}^{n} O_{n}^{2}\right)}=0 \\
& \ldots \\
& \frac{d\left(\sum_{o d 2} C_{o}^{j}\right)}{d\left(\sum_{i=1}^{n} O_{n}^{j}\right)}=0
\end{aligned}
$$

The roots of system of equations (14) can be represented as the following system of equations:

$$
\begin{aligned}
& C_{j i 1}=f\left(P_{i 1}^{1} ; P_{i 1}^{2} ; P_{i 1}^{3} \ldots P_{i 1}^{n}\right) \cdot \sum_{i=1}^{n} O_{i=1}^{1} \\
& C_{j i 2}=f\left(P_{i 2}^{1} ; P_{i 2}^{2} ; P_{i 2}^{3} \ldots P_{i 2}^{n}\right) \cdot \sum_{i=1}^{n} O_{i=2}^{2} \\
& \ldots \\
& C_{j i n}=f\left(P_{i n}^{1} ; P_{i n}^{2} ; P_{i n}^{3} \ldots P_{i n}^{n}\right) \cdot \sum_{i=1}^{n} O_{i=n}^{n}
\end{aligned}
$$

where $P_{i 1}^{1} ; P_{i 1}^{2} ; P_{i 1}^{3} \ldots P_{i n}^{n}$ are factors representing functions of current parameters and modes of the MSW processing line;

$$
\sum_{i=1}^{n} O_{n}^{j}-\text { the total material flow of MSW determines }
$$

the output of each element in the processing line, i.e. costs associated with its manufacturing and maintenance. The process examines the possibility of distributing the main

flow $\sum O_{i j}$ into several independent flows, i.e. setting up several lines working in parallel.

$$
\sum_{i=1}^{n} O_{i j}=O_{j 1}^{1} ; O_{j 2}^{2} ; O_{j 3}^{3} \ldots O_{j n}^{n}
$$

The method of finding the extremum of functions allows achieving complete adequacy in managing decisions in each specific situation.

It is quite obvious that the MSW processing technology option is superior if it has a mobility in the main element (sorting equipment) allowing adapting the process to specific conditions.

Comparison of the cost of MSW processing using a package unit and using the standard technology depending on the MSW volume and transportation distance is give(p) in Figure 10.

Based on the data, the following can be concluded:

- the use of a package unit for MSW sorting is feasible at volumes up to $2 \mathrm{~m}^{3}$ in case the distance between stations is up to $1 \mathrm{~km}$;

- the use of the standard technology involving stationary plants is feasible only in case of large scope of work.

\section{Conclusion}

1. A package unit for MSW sorting is a temporary stationary sorting unit where collection, delivery and sorting are carried out manually. When choosing the standard size of package units, the most important parameters are MSW volume and hand-delivery distance. According to the numerical analysis, the use of package units is most effective for MSW volumes $V \leq 2 \mathrm{~m}^{3}$ and distance of collection and delivery $L \leq 1 \mathrm{~km}$.

2. The main part of any unit for MSW sorting consists of a standard belt conveyor having a width of $0.8 \ldots 1.0 \mathrm{~m}$ to suit anthropometric characteristics of operators; the length of the belt should be consistent with the number of operators collecting particular fractions. The speed of the conveyor belt controls MSW sorting quality; it depends on the speed of human eye and muscle movement. The boundaries of the conveyor belt speed are theoretically established and stay within $V=0.5 \ldots .5 \mathrm{~m} / \mathrm{min}$ limit. Depending on the volumes, the fraction composition and required quality of MSW sorting, it is recommended to adjust the conveyor speed using a variable-frequency electric drive. 
3. Preliminary MSW compacting used to increase the MSW mass upon one-off delivery to a sorting unit significantly complicates the sorting process. At the MSW compression ratio $\xi=4$, time spent on sorting increases up to $30 \%$. When sorting MSW products, the best sequence of MSW fraction collection depends on the MSW morphological composition. The most rational sequence for MSW fraction collection for educational and sport facilities (stadiums, race tracks), recreation centers, etc. is as follows: waste paper; plastic; glass; metal. 


\section{References}

Babanin, I.V. (2005). Justification of necessity and requirements to schemes for segregated collection of municipal waste. Available at: http://waste.com.ua (accessed on: 14.06.2018)

Babanin, I.V. (2006). Evaluating the efficiency of segregated waste collection. Municipal Solid Waste, 7, pp. 40-43.

Bilitewski, B., Dornak, K. (2006). Waste management in Germany. Municipal Solid waste, 10, pp. 54-57.

Bontoux, L., Leone F., Nicolai M. (1996). The recycling industry in the European Union: impediments and prospects. A report prepared by IPTS for the Committee for Environment, Public Health and Consumer Protection of the European Parliament.

Bukhgalter, E.B., Budnikov, B.O., Budnikova, O.A. (2004). Waste management as the most important direction of sustainable development in European Union countries. Industrial Ecology, 10, pp. 45-57.

Chekalin, V.S. (2001). Strategic management in urban economy: study guide. Saint Petersburg: Saint Petersburg State University of Engineering and Economics.

Christensen, T., Cossu, R., Stegmann, R. (1999). Waste management and treatment of municipal and industrial waste. In: Proceedings of 7th International Waste Management and Landfill Symposium, Sardinia.

Council Directive on the prevention of air pollution from new municipal waste incineration plant (1989). Official Journal of the European Communities, 163, pp. 32-36.

Dubois, M., González, A., Knadel, M. (2004). Municipal solid waste treatment in the EU. Environmental Studies, Aarhus University. Fedorov, L.G. (1999). Waste management in large cities and agglomeration settlement systems. Moscow: Prima-Press-M.

Grinin, A.S., Novikov, V.N. (2002). Industrial and municipal waste: storage, disposal, recycling: study guide. Moscow: FAIR-PRESS.

Kasimov, A.M., Semenov, V.T., Aleksandrov, A.N., Kovalenko, A.M. (2007). Municipal solid waste. Technologies and equipment. Problems and solutions. Kharkiv: Kharkiv National Academy of Municipal Economy.

Krasnyansky, M.E. (2007). Waste disposal and recycling: study guide. 2nd edition. Kharkiv: Burun i K., Kiev: KNT.

Krasnyansky, M.E., Belgasem, A., Kalinikhin, O.N. (2004). Analyzing flows of recyclables in municipal solid waste of Donetsk. In: Problems of collection, processing and disposal of waste. Odessa: Odessa Center of Scientific, Technical and Economic Information.

Lyubarskaya, M.A. (2004). MSW management: study guide. Saint Petersburg: Saint Petersburg State University of Engineering and Economics.

Overmann, L.K., Lo, Y.C., Broadgate, J.S. (1999). Waste treatment facility management - restoration of landfills in urban/ sub-urban environments. Environmental impact, aftercare and remediation of landfills, Sardinia, SIWMLS.

Penchuk, V.A., Datsenko, V.M. (2013). Specifics and trends in developing technologies for municipal waste processing. Innovations in Science - Innovations in Education: Proceedings of the International Scientific and Technical Conference "Interstroymekh 2013". Novocherkassk: Platov South-Russian State Polytechnic University (NPI).

Penchuk, V.O., Datsenko, V.M. (2012). Use of package and mobile units for efficient MSW management. In: Proceedings of the National Ecological Forum "Ecology in Industrial Regions", Volume 1.

Pires, A., Martinho, G., Chang, N.-B. (2011). Solid waste management in European countries: a review of systems analysis techniques. Journal of Environmental Management, 92 (4), pp. 1033-1050.

Planning for solid waste \& recycling (2008). City of Boise Planning \& Development Services, pp. 38-39.

Podchezertseva, E.Yu. (2005). Justification of necessity for waste sorting as one of the stages in waste neutralization // In: Proceedings of 4th International Scientific and Practical Conference of Students, Postgraduate Students and Young Scientists "Ecology and Scientific and Technical Progress". Perm: Perm State Technical University.

Veprentsev, I.V. (2006). European approach to waste management. Municipal Solid Waste, 10, pp. 34-36. 